\title{
Adult Angiosarcoma
}

National Cancer Institute

\section{Source}

National Cancer Institute. Adult Angiosarcoma. NCI Thesaurus. Code C9040.

An angiosarcoma occurring in the adult population. 